\title{
Wetland Ecosystem - Interplay of Factors Influencing Microclimate and Seasonal Variation - a Review
}

\author{
Mathews P Raj1*, Reena Susan Philip²
}

Department of Life Sciences, School of Sciences Block II, Jain (Deemed To Be University), Bangalore, India Department of Forensic Sciences, School of Sciences Block II, Jain (Deemed To Be University), Bangalore, India Corresponding author*:pr.mathews@ jainuniversity.ac.in

Received: 25 Oct 2021; Received in revised form: 14 Dec 2021; Accepted: 22 Dec 2021; Available online: 30 Dec 2021 (C)2021 The Author(s). Published by Infogain Publication. This is an open access article under the CC BY license (https://creativecommons.org/licenses/by/4.0/).

\begin{abstract}
Water, is one of the necessities for the survival of human beings, flora, and fauna. Wetlands have been used as a source of water, and as dump grounds for discharging sewage and other human waste. Urbanization and industrialization have led to the overexploitation of water and water bodies making them disappear at an exponential rate. Seasonal variation and anthropogenic activities have a critical influence on the water quality, microclimate, and aquatic diversity. Researches reviewed in this study indicate that the various parameters are interdependent with each other and influence the productivity, biodiversity, and ultimately the micro-climate and seasonal variations of a wetland ecosystem. Physico-chemical parameters studied like $\mathrm{pH}$, temperature, Chlorophyll content, light and phosphate content are known to directly affect productivity and biodiversity. Changes in productivity and biodiversity further affect the microclimate and seasonal variations of a wetland. Moreover, changes in physical parameters are influenced by changes in chemical parameters and vice versa. Also, changes in biodiversity and productivity are inter-dependent on physical and chemical parameters. This study establishes the interactions among various parameters that govern microclimate and seasonal variations. This review lays the foundation for similar studies on wetland ecosystems for better measures towards sustainability and maintenance.
\end{abstract}

Keywords - Limnology, Microclimate, Seasonal variation, Wetland dynamics.

Water is an important source of energy for all living systems on planet earth; it creates an ecosystem for flora and fauna. This vital elementary source of life runs through rivers into the seas and oceans. In urban communities, water is generally stored in catchment areas like small ponds, natural lakes, or even in man-made lakes. The water especially in wetlands like lakes creates an ecosystem, replenishes groundwater thereby regulating the survival of life forms. The dynamics of water quality in these inland water bodies are majorly affected by varied seasons influencing the microclimate of a wide region or a narrow locality. The parameters that influence the microclimate and seasonal variations can be categorized under physicochemical factors, biological factors, anthropogenic influences, etc... The nature and extent of influence can vary depending on the association of these factors to the above dynamics of a wetland. Few of these parameters have a direct influence while the others have an indirect influence. Micro-climate and seasonal variations in wetland dynamics is an important aspect as it is further known to directly or indirectly influence human activities, agriculture, underground water reservoir, and in the long run the local environment. More importantly, most of these factors are interconnected. Hence it is of great significance to carry out Limnological studies to understand the influence of these factors.

This paper tries to understand the influence of such factors on microclimate and seasonal variations of wetlands. The paper discusses the effect of each of these individual factors and their effect in totality. A relationship of interdependence of factors can be established viz that physicochemical factors influence each other and in-turn 
influences the microclimate and seasonal variations. Spatial variation of these factors also plays a key role in the overall changes observed in microclimate. The physicochemical factors studied in this review include temperature, light, $\mathrm{pH}$, transparency, turbidity, pressure, humidity, wind speed, rainfall, and concentrations of chemical entities like phosphates, nitrates, chlorophyll, silica, and mercury. Most of these factors are known to either directly or indirectly influence the productivity and abundance of flora and fauna which in turn affects biodiversity and ill effects like eutrophication. Anthropogenic influences further are known to influence the increase and decrease of chemical factors leading to a drastic effect on productivity and eutrophication. These effects in turn have been shown to influence the microclimate which further is known to influence seasonal variation. This can be predicted to be a cyclic reaction as per the relationship diagram (Fig 1) shown below.

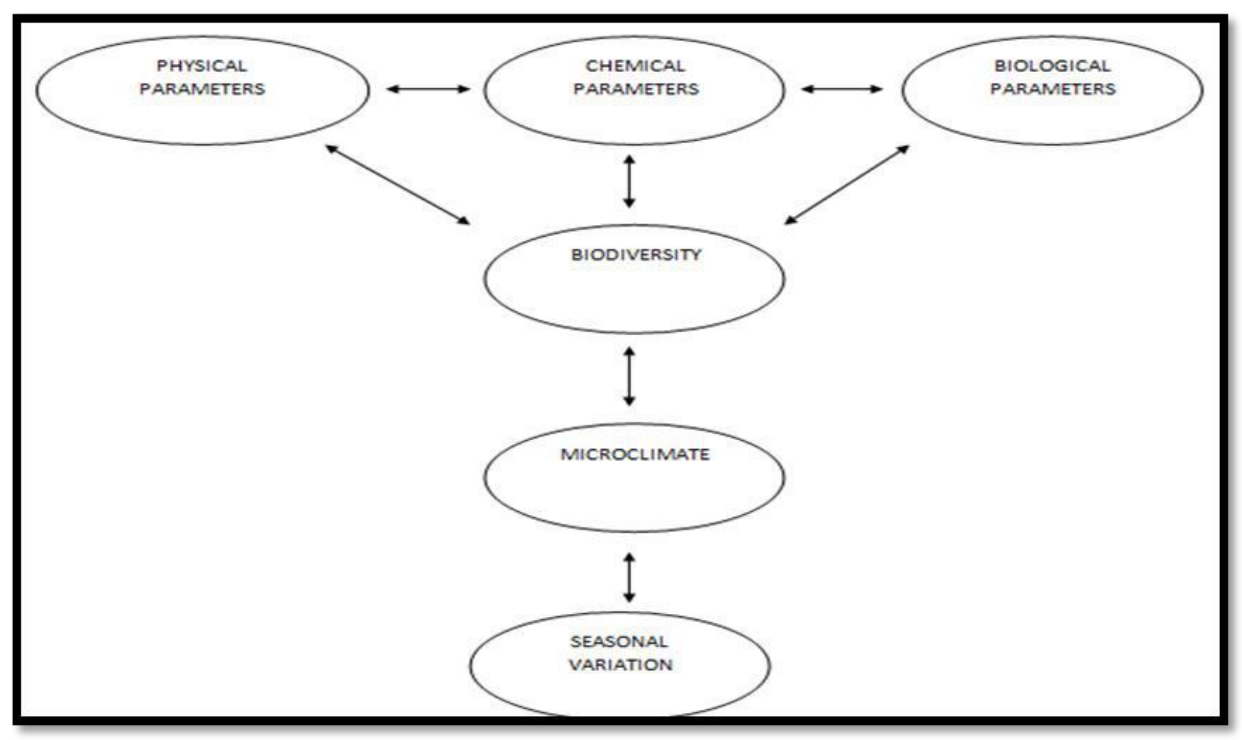

Fig 1: Representation of interdependence of various factors with microclimate and seasonal variation

Understanding such factors and their influence on the microclimate is an important component in the attempts towards sustainability and maintenance of natural resources. This paper helps in gathering an overall perspective on the changing dynamics of the abovementioned parameters and useful insights that can be drawn towards prospects of sustainability and maintenance

\section{A. Physico-chemical Parameters}

$\mathrm{pH}$

$\mathrm{pH}$ is the hydrogen ion concentration that categorizes any aqueous solution into acidic, neutral, and alkaline. Wetlands are also categorized into various types based on $\mathrm{pH}$. $\mathrm{pH}$ governs the nutrients required for the growth and development of hydrophytes and wetland mesophytes. Temperature and dissolved oxygen have a positive correlation (Purohit \& Singh 1980). It is also one of the primary factors influencing the growth of phytoplankton (Ersanli \& Gonulol 2003). The primary productivity of a wetland ecosystem relies positively on water $\mathrm{pH}$ (Hajong \& Ramnujam 2018). It is also a deciding factor concerning the usage of water for various domestic and industrial purposes (Ramanathan \& Amsath 2018).

\section{Temperature}

Temperature is a physical parameter that controls the flow of energy in the universe. It regulates various biogeochemical cycles required for the survival of life forms. In a wetland ecosystem, temperature influences various parameters. The rise in temperature leads to a rise in temperature-dependent physical variables (Ramanathan \& Amsath 2018). A study revealed that temperature has a positive dependence on $\mathrm{pH}$ and dissolved oxygen (Purahit \& Singh 1980). Temperature is also known to impact the density of water (De 2002). It is known to negatively influence concentrations of salts such as phosphates, nitrates, and ammonia (Dar et al. 2013). Water quality and water levels in an aquatic ecosystem are further regulated by temperature (Sahoo et al. 2016). A lake is referred to as monomictic when it does not cool below the temperature of 4 degrees celsius (Purahit \& Singh 1980). Concerning the influence of temperature on various biological systems, it was found that temperature directly influences zooplankton growth (Mecombie 1953; Das 1956; Bamforth 1958; Moitra \& Bhattacharya 1965). Phytoplankton growth is also temperature-dependent (Ersanli \& Gonulol 2003). It affects respiration and controls osmoregulation in aquatic animals (De 2002). Water temperature shows a positive correlation with total 
chlorophyll content (Dar et al. 2013; Giroldo 2014). It strongly influences activities like behavior, respiration, and metabolism in aquatic biota (Gayathri et al. 2013) and also has a direct effect on the growth of algae and aquatic weeds (Zafar 1964). Temperature plays a pivotal role in regulating a wetland ecosystem throughout various seasons; it controls the rate of evaporation, alters wind speed, wind direction, and thereby various attributes of the regional microclimate (Dorche et al. 2018).

\section{Light}

It is a physical parameter that is part of the electromagnetic spectrum which controls the flow of energy on planet earth through the sun being its primary source. Light again is an influencing factor for the well-being of wetlands and biota dependent on these wetlands. Studies indicate that the intensity of light varies according to seasons and changes the physicochemical parameters (Gayathri et al. 2013) high intensity of light generally observed during summers (Giroldo 2014) high light intensity has an ascending impact on the growth rate of members of Cyanophyceae (Araujo 2011), it contributes to the development pattern of benthic fauna (Kabir et al. 2011) and chlorophyll concentration (Giroldo 2014), the low light intensity, on the other hand, has an ascending effect on nitrogen-fixing bacteria (Araujo 2011). Light very evidently and greatly influences the algal growth and diversity in a lake (Hajong \& Ramanujam 2018; Etisa et al. 2018). Thus the primary productivity of a wetland is dependent on light (Hajong \& Ramanujam 2018).

\section{Phosphate}

Phosphate is a macronutrient present in water, soil, and food and it is required for the survival of life forms. In a wetland ecosystem, it regulates the growth of aquatic biota. Phosphate is temperature independent (Dar et al. 2013 and Gayathri et al. 2013) Phosphorous concentrations in lakes tend to rise along with other nutrients (Huszar et al. 2005). Increased phosphate concentration tends to increase chlorophyll concentration (Sahoo et al. 2016) but is known to restrict the growth of submerged aquatic plants (Poquet et al. 2008). An increase in phosphate concentration might be because of nutrient enrichment of the surface water or by the release of phosphate from dead algae and zooplanktons (Heron 1978). Phosphate composition varies with climate and increases during monsoons (Ramanathan \& Amsath 2018). High phosphate inflow into the water body results in eutrophication of the water body (Araujo 2011) and thereby mesotrophic water bodies can turn out to be eutrophic (Garg et al. 2010).

\section{Nitrate}

Nitrate is a chemical nutrient required by phytoplanktons and it forms a major component of agricultural fertilizers. Anthropogenic activity leads to nitrate accumulation in a wetland ecosystem (Mishra et al. 2017). A study indicates the rise in other nutrient factors in association with the increasing concentration of nitrates (Huszar et al. 2005). Nitrates are also believed to vary negatively with temperature (Gayathri et al. 2013; Dar et al. 2013).

\section{Transparency and turbidity}

Turbidity is a measurement of murkiness in fluids. It indicates transparency and opaqueness of a water body which in turn determines the intensity of incident light reaching the benthic zone. Several studies have been carried out to understand the same. Transparency and turbidity are negatively interdependent with temperature (Gayathri et al. 2013; Hajong \& Ramnujam 2018). Transparency is a prominent physical parameter that impacts and increases the productivity in a water body (Jayaweera \& Asaeda 1996; Wei et al. 2004; Kuehl \& Troelstrup 2013; Sukla et al. 2013; Balogun et al. 2014). Depth impacts the turbidity of a water body (Giroldo 2014) studies indicate a change in phytoplankton diversity with turbidity. Cyanophyceae members have been found in abundance in areas receiving sunlight as against nitrogenfixing bacteria in low light regions (Araujo 2011; Giroldo 2014).

6. Pressure, humidity, wind speed, and rainfall

Atmospheric pressure over a water body is influenced by physical parameters like humidity, wind speed, and precipitation. The microclimate of a region is affected by wind speed and direction which in turn is dependent on temperature and dissolved oxygen (Dorche et al. 2018). Water levels and quality in an aquatic ecosystem are regulated by rainfall (Sahoo et al. 2016). The algal productivity varies concerning varying pressure (Agrawal 1999). The chlorophyll content of plants is also known to be influenced by the regional microclimate of a wetland ecosystem (Sahoo et al. 2016).

\section{Chlorophyll}

The total chlorophyll content of a plant determines its productivity. In an aquatic ecosystem, the total chlorophyll content is said to be dependent on physical parameters like water temperature and pH (Dar et al. 2013; Giroldo 2014). However, chlorophyll content was found to be independent of dissolved oxygen (Giroldo 2014). Chlorophyll content varies according to seasons (Araujo 2011, Hajong \& Ramanujam 2018) Spectrophotometric analysis reported high chlorophyll pigments in submerged plants in comparison with floating hydrophytes (Dar et al. 2013).

8. Dissolved reactive silica 
Silica is one of the elements found in soil that leaches out into the water and is known to influence phytoplankton. A study indicates high concentrations of silica during summer as compared to other seasons the study also reveals the concentration-dependent influence of silica on the growth rate of diatoms (Araujo 2011).

\section{Mercury}

Mercury is a liquid metal pollutant found in an aquatic ecosystem due to anthropogenic activity. It is found that aquatic flora and fauna accumulate mercury in the form of methylmercury, Methylation, and demethylation of mercury vary according to seasons and it was found to be increasing during summer seasons (Korthal \& Winfrey 1987)

\section{Biological Parameters}

Wetland Biodiversity is the variety and variability of life in an aquatic ecosystem; it is inclusive of phytoplanktons, zooplanktons, hydrophytes, and terrestrial mesophytes. Phytoplanktons are autotrophic members which form the base for primary productivity of a freshwater ecosystem thereby regulating several aquatic food webs. Phytoplanktons play a decisive role in maintaining the fitness of a wetland ecosystem (Lopes et al. 2005). Zooplanktons are heterotrophic organisms that are majorly dependent on phytoplanktons. The growth, development, and productivity of phytoplankton are determined by several physical and chemical parameters. Physical parameters include $\mathrm{pH}$, temperature, conductivity, light intensity, pressure, transparency, depth, and turbidity. Of these, phytoplankton productivity is negatively influenced by turbidity and depth (Giroldo 2014), while the rest of the parameters have a positive influence on the same. Dissolved oxygen, chlorides, phosphates, sodium, potassium, nitrates, silica, and mercury are a few of the chemical parameters that determine wetland diversity. Cyanophyceae, Bacillariophyceae, Dinophyceae, Chlorophyceae, Chrysophyceae, Zygnematophyceae, Trebouxiophyceae, and Xanthophyceae are the common phytoplankton members while Cladocerans and Rotifers are the common zooplanktons reported in aquatic ecosystems (Mecombie 1953; Das 1956; Bamforth 1958; Zafar 1964; Moitra \& Bhattacharya 1965; Agrawal 1999; Ersanli \& Gonulol 2003; Dixit et al.2005; Reynold et al. 2006; Araujo 2011; Etisa et al. 2018; Hajong \& Ramanujam 2018; Dorche et al. 2018). Food production and nutrient cycle regulation in a wetland are controlled by phytoplanktons (Fathi et al. 2001; Khan 2003). Wetland biodiversity is subjective to seasonal variations in physical and chemical parameters. A study has reported high phytoplankton density during summer as compared to winter (Giroldo 2014). Eichornnia crassipes, Lemna minor, Sagitaria latifolia, Hydro-cotyleranunculoids, and Cyprus are the most abundant floating hydrophytes in the wetland ecosystem while the terrestrial mesophytes include Hibiscus tiliaceus, Ipomoea pescaprae, Terminalia catapa, and Typha latifolia(Mishra et al. 2017; Leidonald 2019).

\section{Productivity}

Primary productivity is defined as the amount of organic matter consumed during respiration and the rate of total photosynthesis. Productivity is dependent on water quality, diversity, and species abundance. Diversity of flora and fauna are further influenced by physicochemical parameters like transparency, alkalinity, temperature and dissolved oxygen (Jayaweera \&Asaeda 1996; Wei et al. 2004; Kuehl \& Troelstrup 2013; Sukla et al. 2013; Balogun et al. 2014; Hajong \& Ramnujam 2018). Productivity was found to be high in shallow regions as compared to deeper zones in a water body due to nutrient regulation by sediments and macrophytic growth (Sontakke \& Mokashe 2014).

\section{Anthropogenic influences}

Anthropogeny is the negative influence of human activities on the environment. It is responsible for the formation of recalcitrant entities. Deterioration of aquatic ecosystems can be traced to anthropogenic wastewater, agricultural run-offs, catchment area, medical waste, and industrial discharge (Kabir et al. 2011; Najar \& Basheer 2012; Nyairo et al. 2015; Mishra et al. 2017; Sudarshan 2019). Human activities influence water quality in wetlands which in turn is responsible for seasonal variations (Kabir et al. 2011). Wetland ecosystems can be demarcated into clear-cut zones based on the extent of the negative influence by the anthropogenic activity which is reflected in the diversity and abundance of flora and fauna (Nikoloaidis et al. 1996; Kun li et al. 2017).

\section{Microclimate}

A microclimate is the prevalent atmospheric parameters over a locality that is contributed by temporal and vertical variation in humidity, temperature, and dissolved oxygen, rate of evaporation, wind speed, wind direction, and nutrient flow (Dorche et al. 2018). Wetlands are also known to regulate the microclimate of a region in its closed vicinity. Variations in microclimate over a wetland are governed by anthropogenic stress (Poquet et al. 2008; KunLi et al. 2017; Sudarshan 2019). Water quality and water levels are influenced by the rate of precipitation which in turn affects the wetland productivity. Unaltered aquatic ecosystems are lesser prone to eutrophication due to recharging and recycling of water which is not possible in the case of man-made aquatic bodies (Gorniak \& Piekarski 2002; Sahoo et al. 2016). Seasonal variations in 
atmospheric gases result in demethylation, which further contributes to nutrient cycling, phytoplankton, and floral diversity implying the health of an aquatic ecosystem (Korthal \& Winfrey 1987; Kennedy 1999; Lopes et al. 2005; Sudarshan 2019).

\section{Spatial Variation}

Spatial geometry is the geographical demarcation of a wetland ecosystem based on the variation in chemical nutrients and biodiversity. Anthropogenic activities around an aquatic ecosystem result in changes in water quality leading to spatial and seasonal variation, studies indicate variations in growth and development, diversity of phytoplanktons, and hydrophytes (Kun Li et al. 2017). The spatial variation of a water body is regulated by the hydrology and reed beds (Huszar 1996; Nikoloadis et al. 1996). Extensive overgrowth of hydrophytes as a result of human activities has led to ecological succession which further negatively influences the faunal and floral diversity (Mishra et al. 2017). Spatial variation and dimensions play a key role in strategizing the restoration and management of wetland ecosystems (Dorche et al. 2018).

\section{RESULTS}

This review paper has successfully gauged the interactions among the various parameters that influence the microclimate and seasonal variations in a wetland ecosystem. Of all the parameters studied $\mathrm{pH}$, chlorophyll content, temperature, light, and phosphate content of water are found to directly affect productivity by altering biodiversity of the wetland while parameters like pressure, humidity, wind speed, and rainfall are found to directly affect the microclimate of the given wetland. Factors like turbidity have been shown to negatively influence the growth of plants and hence the biodiversity and further productivity. Anthropogenic activities lead to a serious rise in chemical factors which further leads to a rapid increase in productivity. Studies have shown that an unchecked increase in productivity leads to eutrophication and in extreme scenarios loss of such wetland ecosystems due to ecological succession. Few studies reviewed reveal that productivity, a shift in biodiversity, eutrophication brings about a change in a microclimate which in turn results in rapid seasonal variations across the wetland ecosystem. Monitoring changes in the microclimate and seasonal variations of a wetland ecosystem is an important aspect of the maintenance and sustainable use of such wetlands in both urban and rural scenarios.

\section{DISCUSSION AND CONCLUSION}

Wetlands are water catchment areas; it includes freshwater bodies such as lakes, ponds, tanks, and rivers. These catchment areas support life forms that range from microscopic phytoplankton to diverse higher forms of flora and fauna. They serve as a source of water to humans and animals, they also function to replenish the groundwater table and act as natural sewage treatment zones. Wetlands contribute towards building an ecosystem and maintain homeostasis in the environment thereby making them a natural and a national asset. These aquatic ecosystems are known to alter atmospheric gases, humidity, and temperature thereby governing the wind speed and direction. These characters of a wetland contribute to regulating the microclimate of a locality and thus influence the seasons of a region. The review focuses on anthropogenic influence characterizing the quality of water. Various research studies indicate that there is a positive correlation established between $\mathrm{pH}$, temperature, dissolved oxygen, phytoplankton diversity, and productivity. It governs respiration and osmoregulation in aquatic flora and fauna, while a few studies indicate chemical nutrients like nitrates, phosphates, alkaline earth metals, and heavy metals have a negative correlation with physical parameters. These physicochemical characters affect the functionality of the plant pigments and are said to have a direct impact on the productivity of an aquatic ecosystem and can infer the fitness of the same. Productivity varies concerning different zones in an aquatic ecosystem and is also influenced by varying seasons. Phytoplankton and zooplankton growth is said to vary in abundance with anthropogenic impact and seasonal dissimilarity. Phytoplankton diversity is high during the summer seasons in comparison with the other seasons. The growth and development of wetland-dependent plants and animals are regulated by these phytoplanktons since they are involved in controlling the biogeochemical cycles and production of food. An increase in physicochemical parameters and productivity shoots up the growth of aquatic weeds which blocks the entry of sunlight affecting underwater life forms leading to their death and altering the water quality. This is followed by the growth of terrestrial mesophytes dependent on these wetlands resulting in ecological succession over a water body resultant of which can lead to slow deterioration of overall water quality and death of a wetland in turn resulting in loss of an entire aquatic ecosystem. Various studies are indicative of the fact that anthropogenic stress-mediated variation in physical and chemical parameters leads to ecological succession. Ecological succession over a wetland is dependent on spatial geometry. This is due to spatial variation in chemical and physical qualities and anthropogenic activities across a water body. The above- 
discussed factors govern the microclimate over a wetland thereby having a critical influence on the seasons of a narrow region. Thus the above review suggests physicochemical, biological qualities and parameters of biodiversity that vary with human influence and varying seasons, converting the wetlands into cesspools which are reflected through changes in the microclimate and seasons over a narrow belt which in turn has a critical impact on global warming. The need of the hour is therefore to protect and conserve these aquatic ecosystems from further deterioration for maintenance of a homeostatic environment.

\section{REFERENCES}

[1] Agrawal S.C. 1999 Limnology, APH Publishing Corporation. Retrieved from https://www.biblio.com/

[2] Ahmed V., Parveen S., Khan A.A., Kabir H.A., Mola, H.R.A. \& Ganai A.H. 2011 Zooplankton population in relation to physico-chemical factors of sewage fed pond of Aligarth (UP), India. Biology and Medicine, 3(2): 33634. Retrieved from https://www.longdom.org/

[3] Andrade R.D.R \& Giroldo D. 2014 Limnological characterisation and phytoplankton seasonal variation in a subtropical shallow lake (Guaiba Lake, Brazil): a long-term study. Acta Limnologica Brasiliensia, vol. 26, no. 4, p. 442456. https://doi.org/10.1590/s2179-975x2014000400011

[4] Bamforth S. S. 1958 Ecological studies on the planktonic Protozoa of a small artificial pond. Limnology and Oceanography, $3: 398-412$ https://doi.org/10.4319/lo.1958.3.4.0398

[5] Balogun K.J., Adedeji A.K., \& Ladigbolu I.A. 2014 Primary production estimation in the euphotic zone of a tropical harbor ecosystem Nigeria. International Journal of Scientific and Research Publication, 4(8):1-8. Retrieved from http://www.ijsrp.org/

[6] De A.K. 1972 Environmental Chemistry. 4th edn, New Age International Publication, New Delhi, pp.231-232. Retrieved from http://files.stupidsid.com/

[7] Etisa D., Nega R. \& Lule W. 2018 Seasonal Variation of Microalgae Diversity in Lake Abaya, Ethiopia. International Journal of Oceanography \& Aquaculture, Volume 2, Issue 5, ISSN: 2577-4050. https://doi.org/10.23880/ijoac-16000150

[8] Das S. M., 1956 A Quantitative studies on qualitative and quantitative fluctuations of plankton in two Kumaon lakes, Nainital and Bhimtal (India). Acta Hydrobiolica. 2(1): 9-17. Retrieved from https://www.environmentaljournal.org/

[9] Dar N.A., Pandit A.K. \& Ganai B.A. 2013 Seasonal Variation in the Pigment Content of Dominant Macrophytes from Wular lake, Kashmir Himalaya, India. Biochemistry and Pharmacology, volume 2 issue 4 . https://doi.org/10.4172/2167-0501.1000124

[10] Dixit S., Gupta S. K. \& Tiwari S. 2005 Nutrient overloading of fresh water lake of Bhopal, India. Electronic Green Journal, 1(21). 1-8. https://doi.org/10.5070/g312110588

[11] Eisa Ebrahimi Dorche., Mojgan Zare Shahraki., Omidvar Farhadian. \& Yazdan Keivany. 2018 Seasonal Variations Of
Plankton Structure As Bioindicators In Zayandehrud Dam Lake, Iran. Limnological Review, 18, 4: 157-165. https://doi.org/10.2478/limre-2018-0017

[12] Eric T. Korthalst \& Michael R. Winfrey. 1987 Seasonal and Spatial Variations in Mercury Methylation and Demethylation in an Oligotrophic Lake. Applied and Environmental Microbiology, Volume 53, Pg. 2397-2404. https://doi.org/10.1128/aem.53.10.2397-2404.1987

[13] Elif Ersanl \& Arif Gönülol. 2003 Study on the Phytoplankton and Seasonal Variation of Lake Simenit (Terme - Samsun, Turkey). Turkish Journal of Fisheries and Aquatic Sciences, 3: 29-39. https://doi.org/10.1080/02705060.2005.9664770

[14] Fathi A.A., Abdelzaher H.M.A., Flower R.J., Ramdani M. \& Kraiem M.M. 2001 Phytoplankton communities of North African wetland lakes. The Cassarina Project, Aquatic Ecology, 35(3): 303-318. Retrieved from https://www.researchgate.net/

[15] Araujo F.G., Azevedo M.C.C.D. \& Ferreira M.D.N.L. 2011 Seasonal changes and spatial variation in the water quality of a eutrophic tropical reservoir determined by the Inflowing River. Lake and Reservoir Management, pg 343 - 354 ISSN: 1040-2381. https://doi.org/10.1080/07438141.2011.627753

[16] Gajanan K. Sontakke \& Satish S. Mokashe 2014 Seasonal variation in primary productivity of two freshwater lakes of Aurangabad district, Maharashtra, India. International Journal of Fauna and Biological Studies 1 (6): 07-10 ISSN 2347-2677. Retrieved from https://www.faunajournal.com/

[17] Garg R.K., Rao R.J., Uchchariya D., Shukla G. \& Saksena D.N. 2010 Seasonal variations in water quality and major threats to Ramsagar reservoir, India. African Journal of Environmental Science and Technology, Vol. 4(2), pp. 061076. Retrieved from https://www.ajol.info/

[18] Gorniak K. P. 2002 Seasonal and Multiannual Changes of Water Levels in Lakes of North eastern Poland. Polish Journal of Environmental Studies, Vol. 11, No. 4 (2002), 349-354. Retrieved from http://www.pjoes.com/

[19] Jeppesen E., Sondergaard M., Mazzeo N., Meerhoff M., Branco C., Huszar V. \& Scasso F. 2005 Lake restoration and bio manipulation in temperate lakes: relevance for subtropical and tropical lakes. In: Restoration and management of tropical eutrophic lakes (Eds.: M.V. Reddy). Oxford and IBH Publishing Co. Pvt. Ltd., New Delhi. pp. 331-349. https://doi.org/10.1201/9781482294484

[20] Jayaweera M \& Asaeda T. 1996 Modeling of biomanipulation in shallow, eutrophic lakes: an application to Lake Bleiswijkse Zoom. The Netherlands. Ecological Modelling, 85:113-127. https://doi.org/10.1016/03043800(94)00153-7

[21] Kennedy R.H. 1999 Reservoir design and operation: Limnological implications and management opportunities, Tundisi J.G, Straškraba M. (eds), Theoretical reservoir ecology and its applications, Backhuys, Leiden: 1-28. Retrieved from https://www.scielo.br/

[22] Khan T.A. 2003 Limnology of four saline lakes in western Victoria, Australia. Limnologica 33(4), 327-339. https://doi.org/10.1016/s0075-9511(03)80026-9 
[23] Kuehl L.C. \& Troelstrup N.H. 2013 Relationship between net primary production, water transparency, chlorophyll a and total phosphorus in Oak Lake, Brookings County, South Dakota. Proceedings -South Dakota Academy of Science, 92:67-78. Retrieved from https://scholar.google.com/

[24] Kun Li., Ling Wang., Zhaohua Li., Yujing Xie., Xiangrong Wang. \& Qing Fang. 2017 Exploring the Spatial-Seasonal Dynamics of Water Quality, Submerged Aquatic Plants and their Influencing Factors in Different Areas of a Lake. Water, pg 1-17. https://doi.org/10.3390/w9090707

[25] Leidonald R., Lesmana I., Muhtadi A. \& Desrita 2019 Biodiversity flora and fauna in tropical tidal lake. IOP Conference Series: Earth and Environmental Science, 260,012105 . https://doi.org/10.1088/17551315/260/1/012105

[26] Lopes M.R.M., Bicudo C.E.M.\& Ferragut M.C. 2005 Short term spatial and temporal variation of phytoplankton in a shallow tropical oligotrophic reservoir, southeast Brazil. Hydrobiologia, 542(1): 235-247. https://doi.org/10.1007/s10750-004-8332-z

[27] Mackereth F.Y.H., Heron J.G. \& Talling J.J. 1978 Water analysis some revised methods for limnologist. Ambleside: Freshwater Biological Association. Oxford (UK): Blackwell Scientific Publication. https://doi.org/10.1002/iroh.19790640404

[28] Mecombie, A. M. 1953 Factors influencing the growth of phytoplankton. Journal of the Fisheries Research Board of Canada, 10 : 253-282. https://doi.org/10.1139/f53-019

[29] Mishra G.S., James A., Paliwal H.B. \& Kumar H. 2017 Physico-Chemical, Biological Properties and Biodiversity of Aquatic Plant Species In Macferson Lake Allahabad, U.P. India, Current world environment, ISSN: 0973-4929, Vol. 12, No. (3) 2017, Pg. 630-634. https://doi.org/10.12944/cwe.12.3.14

[30] Moitra, S. K. \& Bhattacharya B. K. 1965 Some hydrological factors affecting plankton production in a fresh pond in Kalyani, West Bengal, India. Ichthyologica.4: 8-12. Retrieved from https://scholar.google.lu/

[31] Najar A. \& Basheer A. 2012 Assessment of seasonal variation in water quality of Dal Lake (Kashmir, India) using multivariate statistical techniques WIT. Transactions on Ecology and The Environment, Vol 164. https://doi.org/10.2495/wp120111

[32] Nikolaidis N.P., Koussouris T., Murray T.E., Bertahas I., Diapoulis A. \& Gritzalis K. 1996 Seasonal Variation of Nutrients and Heavy Metals in Phragmites australis of Lake Trichonis, Greece. Lake and Reservoir Management, 12:3, 364-370. https://doi.org/10.1080/07438149609354277

[33] Nyairo W.N., Owuor P.O. \& Kengara F.O. 2015 Effect of anthropogenic activities on the water quality of Amala and Nyangores tributaries of River Mara in Kenya. Environmental Monitoring and Assessment, 187, 691. https://doi.org/10.1007/s10661-015-4913-8

[34] Pranita Hajong. \& Papiya Ramanujam. 2018 Seasonal variation in algal diversity and productivity in Dachi lake, Meghalaya Journal of Algal Biomass Utilization, 9(2), 9-24. Retrieved from http://www.jalgalbiomass.com/
[35] Poquet J.M., Mezquita F., Rueda J. \& Miracle M.R. 2008 Loss of Ostracoda biodiversity in Western Mediterranean wetlands. Aquatic Conservation Marine and Freshwater Ecosystems, 18, 280-296. https://doi.org/10.1002/aqc.831

[36] Purohit R. \& Singh S.P. 1981 Seasonal Variation in Physico-Chemical Limnology of shallow zones of Nainital Lake, Western Himalaya(India). Proceedings of Indian National Science Academy, B47, No. 2, pp 194- 203. Retrieved from https://insa.nic.in/

[37] Ramanathan S. \& Amsath A. 2018 Seasonal Variations in Physico-Chemical Parameters of Puthukulam Pond, Pudukkottai, Tamilnadu. Research Journal of Life sciences, Bioinformatics, Pharmaceutical and Chemical sciences, 4(6), Pg.656. Retrieved from http://www.rjlbpcs.com/

[38] Reynolds C.S. 2006 The ecology of phytoplankton. Cambridge University Press, UK. https://doi.org/10.1017/cbo9780511542145.009

[39] Gayathri S., N. Latha N \& Mohan M.R. 2013 Impact of Climate Change on Water Quality of Shoolkere Lake, Bangalore, Journal of Academia and Industrial Research (JAIR), Volume 2, Issue 6, pg 362- 368. Retrieved from https://www.semanticscholar.org/

[40] Sahoo P.K., Guimaraes J.T.F., Filho P.W.M., Silva M.S, Silva Junior R.O. \& Pessim G. 2016 Influence of Seasonal Variation on the Hydro Biogeochemical characteristics of two upland lakes in the south eastern amazon, Brazil. Brazilian Academy of Sciences, 88, 2211-2227. https://doi.org/10.1590/0001-3765201620160354

[41] Shannon C.E. \& Reid W.J. 2003 The mathematical theory of communication. University of Illinois Press, Illinois, USA.

[42] Sudarshan P., Mahesh M.K. \& Ramachandra T.V. 2019 Assessment of Seasonal Variation in Water Quality and Water Quality Index (WQI) of Hebbal Lake, Bangalore, India. Environment and Ecology 37, pg: 309-317. Retrieved from https://www.sciencedirect.com/

[43] Sukla B., Patra A.K. \& Panda R.P. 2013 Primary Productivity in River Birupa, India. Proceedings of the National Academy of Sciences India, Section B, Biological Science, 83(4), 593-602. https://doi.org/10.1007/s40011$\underline{013-0165-y}$

[44] Wei H., Sun J., Moll A., \& Zhao L. 2004 Phytoplankton dynamics in the Bohai Sea observation and modelling. Journal of Marine System, 44:233-251. https://doi.org/10.1016/j.jmarsys.2003.09.012

[45]Zafar A.R. 1964. On the ecology of algae in certain fish ponds of Hyderabad, India. Distribution of Unicellular and colonial forms. Hydrobiologia, 24: 556565. https://doi.org/10.1007/bf00142002 